\section{Mapping shallow subsurface to identify sinkhole formation in urban areas using ground penetration radar: a case study from Hyderabad, India}

\author{
Anand K. Pandey*, Jonti Gogoi and \\ Prabha Pandey \\ Academy of Scientific Innovation and Research, \\ CSIR-National Geophysical Research Institute, Uppal Road, \\ Hyderabad 500 007, India
}

Ground penetrating radar (GPR) survey can be used to image geological hazards such as cavities, faults, fissures and also for identifying buried utilities. Sinkholes formed in the Secunderabad-Patny stretch road, Hyderabad, India were speculated to have been caused due to leaking from the sewer pipe. GPR survey using $200 \mathrm{MHz}$ antenna was used in order to study the sinkholes formed in the collapsed area. GPR profiles were taken both parallel to and perpendicular to the road section to get a complete 3D visualization. Subsurface images acquired the marked position of the manholes, cavities, loose soil, different utilities, and sewer pipeline in the area. The results showed that there was no leaking in the sewer pipeline, instead, a water pipeline was damaged due to poor maintenance. Thus, GPR can be efficiently used to delineate the subsurface infrastructure and has further played an important role in identifying, delineating the zone of sinkhole in a busy street in Secunderabad.

Keywords: Civic utilities, ground penetrating radar, shallow subsurface, sinkhole.

RAPID urbanization in the past decade has led to the expansion of civic infrastructure in the landscape of evolving cities, often without comprehensive master plan, to cope with the rising demands in India. The expansion of urban infrastructure and civic amenities invariably harness the top soil and shallow subsurface of scarce land. Most civic amenities including pipelines for drinking water, sewer, optical cables and at places natural gas, often coexist with the road network including flyovers and underpass in the cities. Often, haphazard overlaying and poor maintenance of pipelines cause damage to previously existing civic utilities. These utilities experience enhanced strain during monsoon period or during extreme weather events when heavy precipitation causes excess flow through drains producing wear and tear to the utilities, and also make the top soil vulnerable to damage by water logging and surface runoff. Development of large cavity and sinkholes due to leakage from sewage and/or drinking water pipes that weaken and form voids in the adjoining soil/rocks leading to collapse of the overlying

\footnotetext{
*For correspondence. (e-mail: akpandey@ngri.res.in)
}

layers, are the commonly observed phenomenon world over ${ }^{1-4}$. Sinkholes are sub-circular chasms/surface depressions propagating upward from natural or anthropogenic underground cavities including karst terrain, deep piping or mixed genesis ${ }^{5-9}$.

Formation of sinkholes in urban landscapes in India are commonly reported during monsoon period after heavy precipitation (Figure 1 inset). Sinkholes are also reported from regions affected by shallow underground mining e.g. around abandoned coal mines in central India or during constructions of large infrastructure projects like metro in cities like Delhi (October 2015), Bengaluru (August 2016), Chennai (April 2017) (Figure 1a). The formation of sinkholes is often reported even in the granitic terrain of Hyderabad during monsoon, which are formed by the collapse of top soil due to breach of old sewage pipelines, e.g. Necklace road (2016), Kukatpally and Secunderabad (September-December 2017), Bapuji Nagar road and Shapur Nagar on June 2018 (Figure 1).

On 31 December 2017, a large sinkhole was formed near and Secunderabad clock tower (Figure $2 a$ and $b$ ) over the sewer line of Nizam's era, leading to the speculation that the poor condition of the age-old sewage line might have damaged causing leakage in the shallow subsurface. On request from Managing Director, Hyderabad Metropolitan Water Supply and Sewerage Board (HMWSSB), CSIR-National Geophysical Research Institute (CSIR-NGRI), Hyderabad undertook the study to ascertain the reason behind the sinkhole formation and extent of damage to subsoil and sewage pipeline that caused the leakage, and also to demonstrate the viability of geophysical methods for shallow subsurface mapping for civic assets management ${ }^{10}$. The detection of cavities that have potential to collapse and create sinkholes from leakages in buried pipelines of different utilities in urban environment presents a serious challenge. In order to

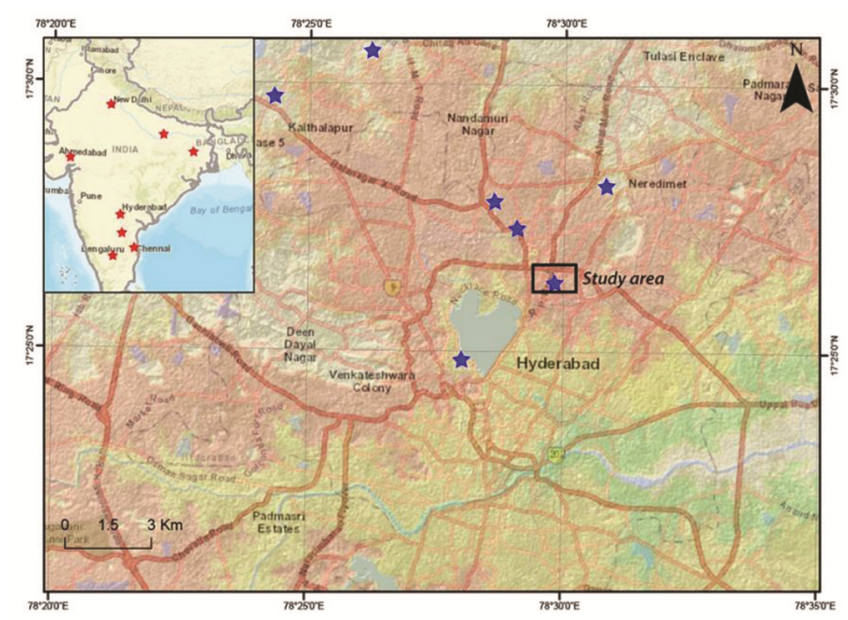

Figure 1. The distribution of recent sinkholes formed after heavy rainfall or near construction sites in urban landscape of India and Hyderabad. Most sinkholes in Hyderabad formed due to damaged pipelines. 


\section{RESEARCH COMMUNICATIONS}

detect these, geophysical reflection methods, both shallow seismic and electromagnetic (EM) survey can be used; however, owing to presence of water leakage, EM survey was preferred. The conventional EM survey involves elaborate layout plan for the experiment and is also limited by availability of space in urban setup. The ground penetrating radar (GPR) survey provides an alternative that can achieve high resolution results for shallow depth without being restricted by portability or stretch of the profile $e^{1,4,9}$. Thus, we undertook a GPR survey on 3 January 2017, for shallow subsurface imaging to detect cavity and leakages as the method is non-destructive and though with some limitations, offers a highly successful technique in various urban settings ${ }^{11-14}$. We present and discuss the findings and challenges in detecting sinkholes and subsurface cavity formation associated with civic utilities in the urban landscape of Hyderabad.

The Hyderabad metropolis grew over the weathered substrate of Palaeoproterozoic granite suite of the eastern Dharwar craton $^{15}$. The urban setup like sewage pipelines and canals were developed in the city during early 19th century under the patronage of Nizams and Britishers. During past couple of decades, a modern city infrastructure grew with the advent of cyber technology that led to an exponential growth of Hyderabad as an urban centre with modern civic utilities. One of the busy stretch of road near Secunderabad clock tower got affected due to the development of multiple sinkholes on 31 December 2016 (Figure $2 a$ and $b$ ) affecting traffic and disruption in water supply in adjoining region.

An $\sim 2 \mathrm{~m}$ deep elongated sinkhole was formed on the road over the sewage line in front of Kamat Hotel's pavement near clock tower (Figure $2 b$ ). The diameter of the sewage pipeline is $\sim 30 \mathrm{~cm}$ and it lies at 3-4 $\mathrm{m}$ depth

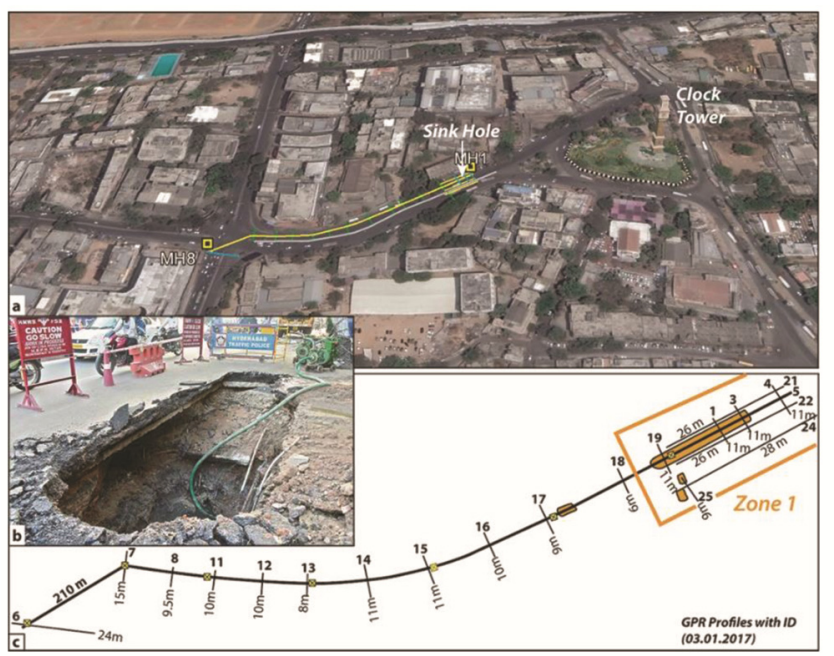

Figure 2. The stretch of the road along Secunderabad-Patny Centre crossing, where the sinkhole was developed and surveyed. The solid black lines mark the ground penetrating radar (GPR) profiles and the solid yellow blocks mark the reported sinkholes. in the weathered granitic top soil. The sewage pipeline drains into the larger $(>40 \mathrm{~cm}$ diameter $)$ sewage pipe at the Patny Centre crossing, which lies $\sim 200 \mathrm{~m}$ away from sinkhole at an elevation difference of $>10$ feet from the clock tower. A couple of small depressions were also developed on the other side of the road divider from where $\sim 4$ inches thick drinking water distribution pipe is present in the direction of sinkhole. The main drinking water pipeline usually lay on the other side of the road away from the sewage pipeline at a shallower depth to avoid contamination. An $\sim 15 \mathrm{~cm}$ asphalt constitute the top of the road and several other utilities like optical fibre cables, shallow water supply and domestic sewage connections lie in the top $50-100 \mathrm{~cm}$, especially towards the sewage pipeline side making the reworked top soil loose. By the time the survey was taken up, the cavity caused by the sinkhole was temporarily closed. It was challenging to identify the leakage zone that caused the development of sinkhole, and so we decided to cover the complete length of sewage drainage till the higher connection at Patny Centre crossing having long profile and multiple cross profiles with optimal separation (Figure $2 a$ and $c$ ). We also planned multiple road parallel and across GPR profiles, around the sinkhole zone to get a three dimensional (3D) perspective of shallow subsurface soil and utilities (Figure $2 c$-zone 1). The GPR data was acquired along 20 profiles with longest profile $(210 \mathrm{~m})$ running parallel to the road over the sewage line from Secunderabad clock tower (Kamat Hotel) to Patny Centre crossing and several cross profiles across the road (Figure 2).

GPR uses high frequency EM energy to transmit discrete pulses and receive the reflected signal ${ }^{16}$ (Figure 3 ). It produces a cross-sectional image based on the propagation, reflection and scattering of EM waves (Figure 3). The behaviour of these EM waves depends on the contrasting dielectric constant, which depends on the soil/rock properties such as, grain size, water content, porosity, etc. The method is successfully used world over to locate underground cavities, caves and fractures formed by damaged civic utilities ${ }^{8,17-21}$. GPR survey is helpful because, it is a portable non-destructive EM method that can produce high resolution subsurface images $^{16}$. The real time output of the scan gives a preliminary information that can be used to change parameters and survey design during the survey.

The EM waves' frequencies in GPR range from $10 \mathrm{MHz}$ to $2.4 \mathrm{GHz}$ and the smaller frequency offer greater penetration depth and vice versa ${ }^{16-18,22}$. The survey required priory dielectric constant of the upper surface where the GPR was placed. The resolution of the image being directly proportional to the frequency, i.e. a high resolution image for shallow depth requires high frequency waves. The penetration depth of the transmitted waves can be determined from the equation

$$
D=c t / \sqrt{ } E r,
$$




\section{RESEARCH COMMUNICATIONS}

where $D$ is the depth of penetration $(\mathrm{m}), c$ the velocity of light in free space, $t$ the wave travel time (nanosec), $E r$ is the dielectric constant $(\mathrm{Neal})^{16}$.

In this study, GSSI SIR 4000 GPR system with $200 \mathrm{MHz}$ central frequency antenna was used (Figure 3). Data was acquired in the continuous mode (distance mode) using a calibrated perimeter of the survey wheel for measuring the distance (Figure 3). The data collection was carried out at $177 \mathrm{scan} / \mathrm{sec}$ and $100 \mathrm{scan} / \mathrm{unit}$ in horizontal scale and 512 sample/scan and $32 \mathrm{bits} / \mathrm{sec}$ in vertical scale. We used the conventional frequency setting while acquiring data, whose high-pass was $1 / 6$ th the antenna frequency and low-pass would be higher than the antenna frequency. The frequency range was set by assigning low-pass (335 MHz) and high-pass $(40 \mathrm{MHz})$ filters. The dielectric value of the upper layer (relative permittivity of asphalt was equal to 6.0) was assigned, which estimated the maximum depth of penetration to be equal to $\sim 5 \mathrm{~m}$. The field data was processed using Radan7 software with the following steps, viz. time zero correction, background removal, finite impulse response (FIR), gain, stretching and signal floor. The time zero correction function was applied to the raw data to detect the ground wave peak positions followed by elimination of the portion above the traces using time shift to bring initial data to exact ground surface. Background removal was applied to remove all the horizontal coherent noises using fullpass background removal. The collected data was full of noises from urban sources. To increase the signal-noise

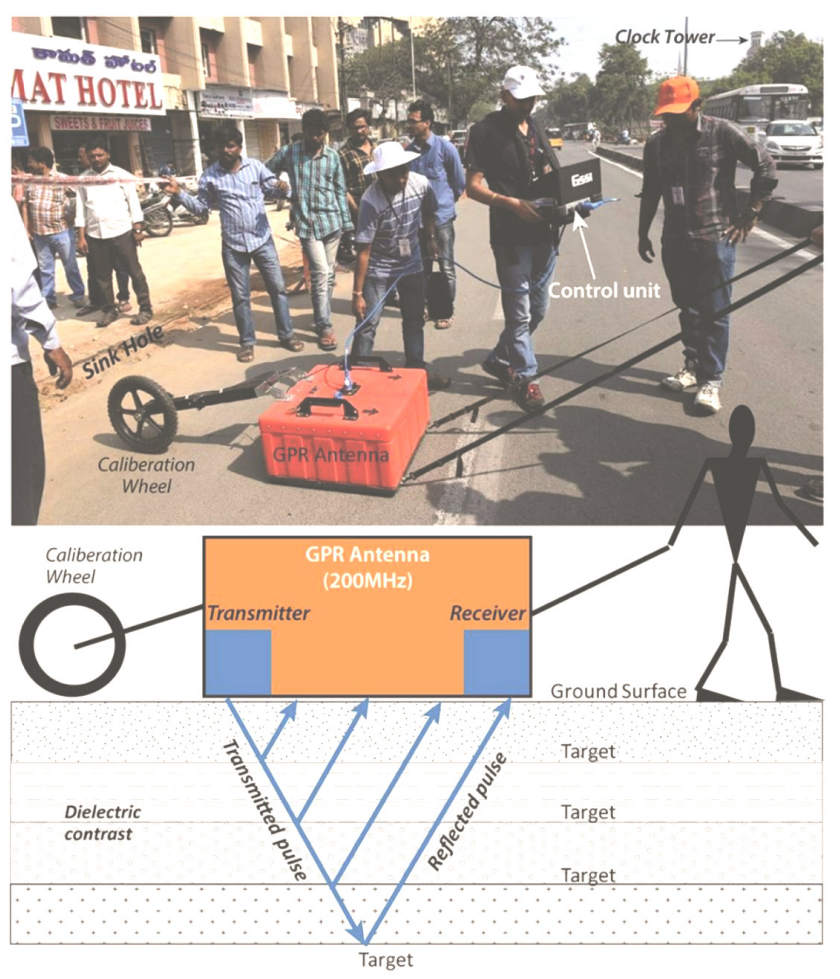

Figure 3. Ray paths from transmitter to receiver showing all the components of the GPR system (modified after Neal) ${ }^{16}$. ratio, low pass $(=250 \mathrm{MHz})$ and high-pass $(=95 \mathrm{MHz})$ filters were applied. The values of filters were decided by the frequency spectrum of the neighbourhood region including spectrum peak. Exponential gain $(\max =76)$ with depth was applied to reduce the fluctuation of amplitude of traces, which reduced with depth. Horizontal stretching was applied to transfer the profile to its original scale. The processed data is reliable up to a certain depth, which is given by the signal floor. The futile data below the signal floor can be clipped from profiles displayed after final processing (Figure 4).

The radar reflection configurations were observed in terms of shape and inclination of reflection, relationship between reflections and reflection continuity ${ }^{16}$. The amplitude of the reflected signal is an important characteristic, mainly in the air-filled void/cavity detection as the dielectric constant of air being 1 shows high contrast in the image and the shape depends on the discontinuous reflector geometry ${ }^{16-18,21,23}$. The cavities filled with other materials showed cone shaped/hyperbolic diffraction pattern from subsurface objects. The voids were interpreted through echoes of reflection profiles ${ }^{19-21}$. Eyuboglu et $a l .^{24}$ constructed an experimental setup in order to mimic the leakage from pipes in the subsurface to check the efficiency of GPR in detecting leakage from pipes in a practical scenario. The difference in the acquired GPR data before and after leakage showed variations in reflection profile in the subsurface formations. Since in this study, the primary focus was to investigate the area for possible leakage and lookout for subsurface anomaly that was caused due to water spill from pipes, the results from the above-mentioned experiment ${ }^{24}$ helped in demarcating the targeted features and also interpret them accordingly on the basis of the site's civic utility setup.

In the Secunderabad-Patny stretch of the road, similar traits as mentioned above were observed. Using the above information and general orientations, size and continuity of the reflection events, we identified sewer/water pipelines, cavities, loose materials and manholes. The loose soil material filled in the sewage trench did not show any characteristic horizontal lithological variation (Figure $5 a$ ). The point source/object-like cross-sectional view of pipeline produced, a hyperbola (Figure $5 a$ and $b$ ) and the pipeline parallel to the profile, showed sharp horizontal dielectric contrast due to voids in the pipe (Figure $5 b$ and $c)^{26}$. The manhole was marked by a signal echo without attenuation showing continuous scope in the line scan (Figure $5 d$ ), whereas, the variable shape of the void produced irregular strong reflection zones. The depth of water pipeline, sewage pipeline along with their sizes were verified with the HMWSSB engineer and site staff. The manholes were physically identified and marked during the survey which were later correlated with the GPR images. These subsurface voids (Figure $5 d-f$ ) showed depth association with the specific pipeline at depths $\sim 2 \mathrm{~m}$ and $3.5 \mathrm{~m}$. The association, geometry and extent of 
RESEARCH COMMUNICATIONS

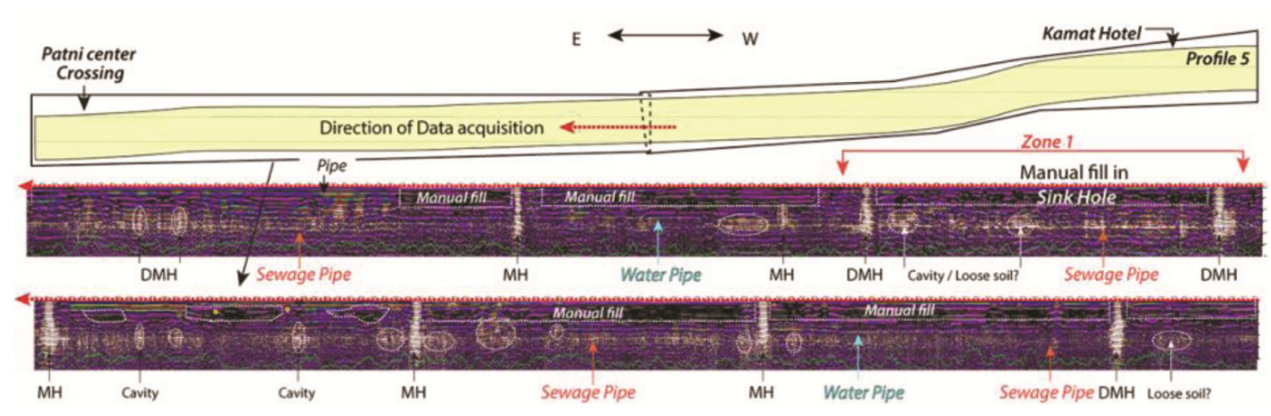

Figure 4. GPR section of profile no. 5 (marked in Figure 2) along the E-W transect. Please note the left section represents the middle panel and the right section is at the bottom. (DMH/MH, Disturbed manhole/manhole).

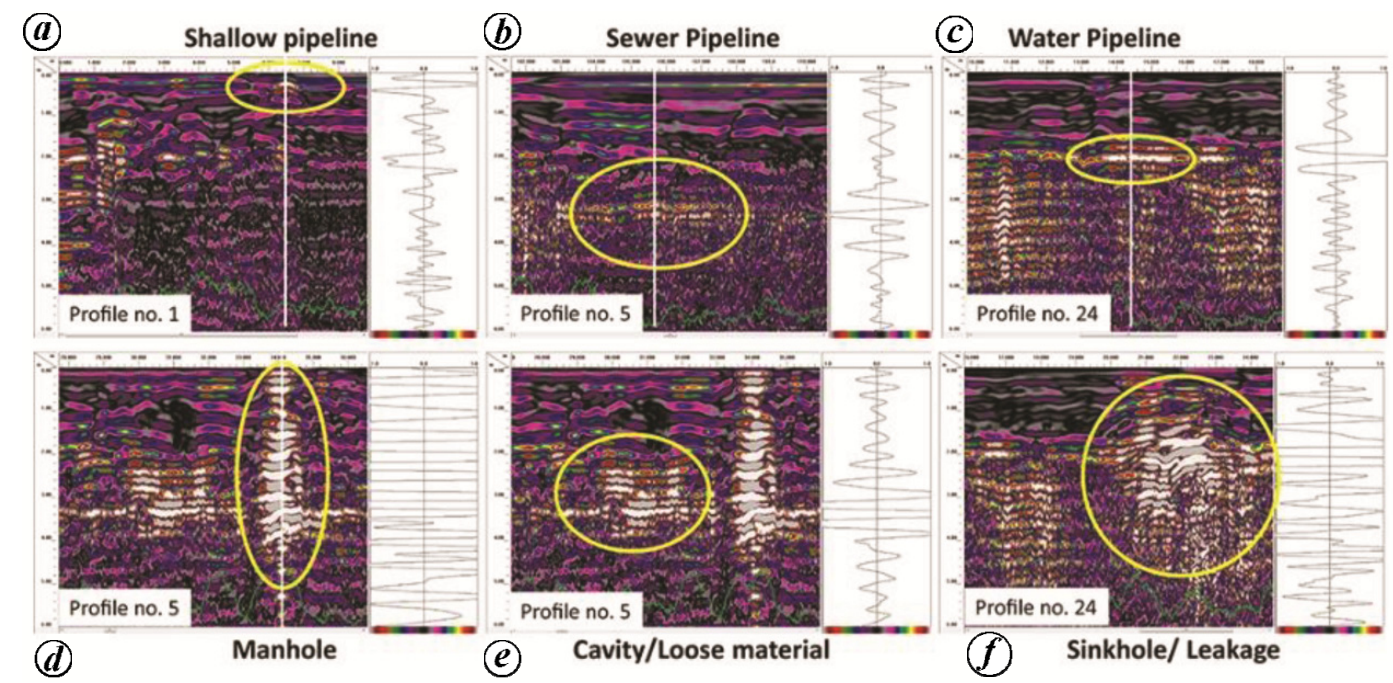

Figure 5. The important civic utility and associated soil features are identified based on signal amplitude variation in the stacked 1-D data along profiles. Please note the image and signal of $(\boldsymbol{a})$ shallow pipeline, $(\boldsymbol{b})$ sewer pipeline at $\sim 3.5 \mathrm{~m},(\boldsymbol{c})$ drinking water pipeline at $\sim 2 \mathrm{~m},(\boldsymbol{d})$ echo signal of void over manhole, $(\boldsymbol{e}$ and $\boldsymbol{f})$ signal perturbation in the small cavity/loose material/sinkhole near leakages.

the cavities are important in understanding their relationship with the leakage in the subsurface. The layers surrounding the leakage seemed to be affected by the water pouring into the layers ${ }^{17}$.

In the GPR profile along the study sections, manholes, separated from each other by $\sim 30 \mathrm{~m}$, are prominently observed as high amplitude reflections as shown in Figure 4 . The profile also highlights all the cavities and loose soil along its cross section. A continuous white line running parallel to the profile joining the lower part of manholes is the sewage pipeline at a depth of $>3 \mathrm{~m}$ and another pipeline observed at $\sim 2 \mathrm{~m}$ depth is identified as the drinking water pipe (Figure 4). The dielectric contrast was more in sewage pipeline probably because of presence of larger air column in thicker pipe which was also confirmed in the cross profiles. Several small zones of cavity were also observed at 2-3 m depth.

To get a $3 \mathrm{D}$ perspective and to detect layouts sewer and water pipelines, loose soil/landfill, cavities and manholes, the sinkholes-affected zone 1 was covered with four E-W profiles namely, 21, 5, 22 and 24 parallel to the road and five N-S profiles, viz. 1, 3, 4, 19 and 25 across the road (Figures 2 and 6). The profile 21 lying towards pavement, showed cavities and manholes extending to $>3 \mathrm{~m}$ depth and the cross-sectional view of water pipelines were observed at $\sim 1 \mathrm{~m}$ depth. The sinkhole extending up to $2-2.5 \mathrm{~m}$ depth with disturbed soil extending towards pavement was visible in profile 1 . The profiles 3 and 4 showed sewage pipe and cavity/saturated loose soil at $\sim 3.5 \mathrm{~m}$ depth. In profile 5 , the sewage pipeline was clearly observed at $\sim 3.5 \mathrm{~m}$ depth and small cavity/loose soil at some of the locations in the sinkhole-affected zone was present between two manholes. The profile 22 , which passed through the middle of the road, did not show any soil degradation. The profile 24 on the other side of the road showed cavity at $2 \mathrm{~m}$ depth associated with the water pipeline. In the cross profiles 25 and 19, the cavity was observed to extend northward to join the sinkhole over the sewage pipeline. The GPR profiles in zone 1 suggested that most of the cavity leading to the main 


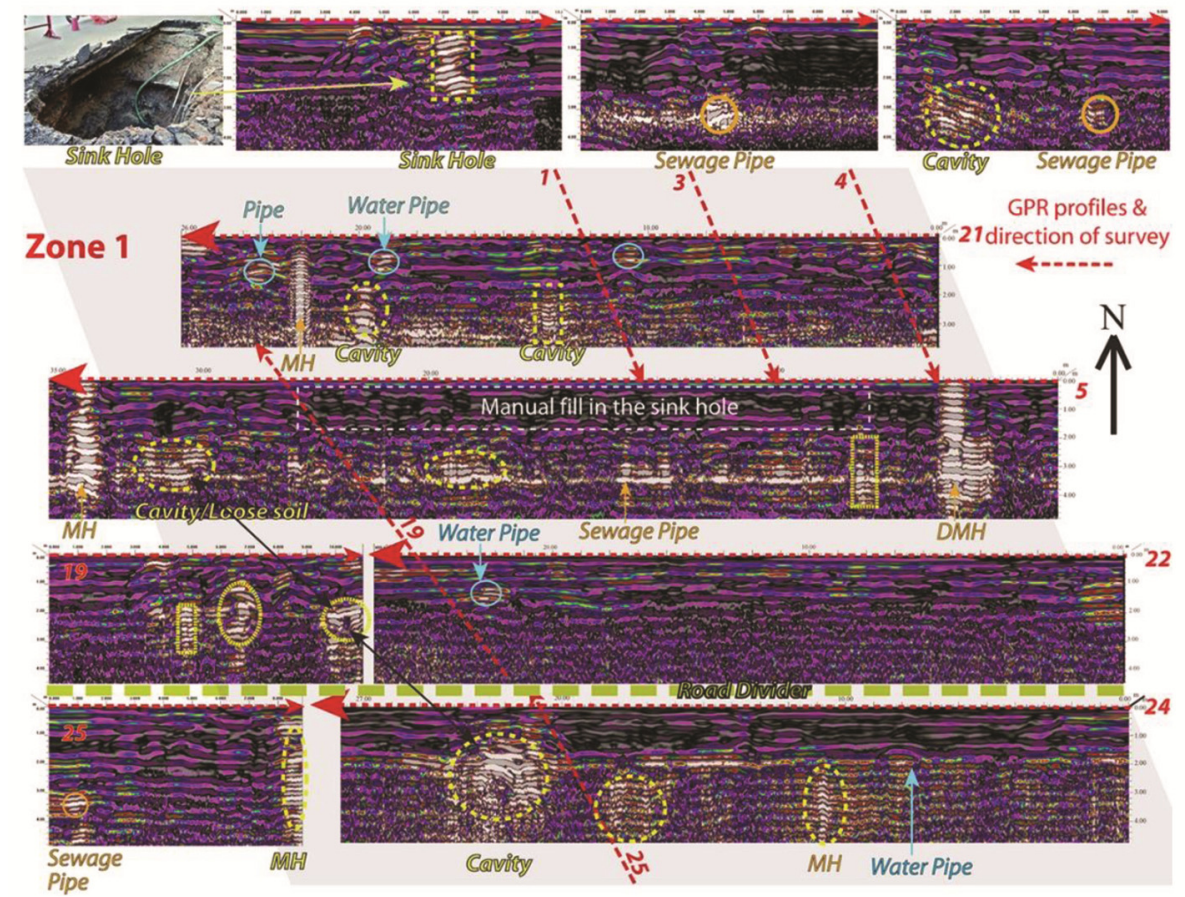

Figure 6. 2-D GPR profiles for zone 1 covering the sinkhole and cavity affected road. The red arrow marks the profile directions. MH, manhole.

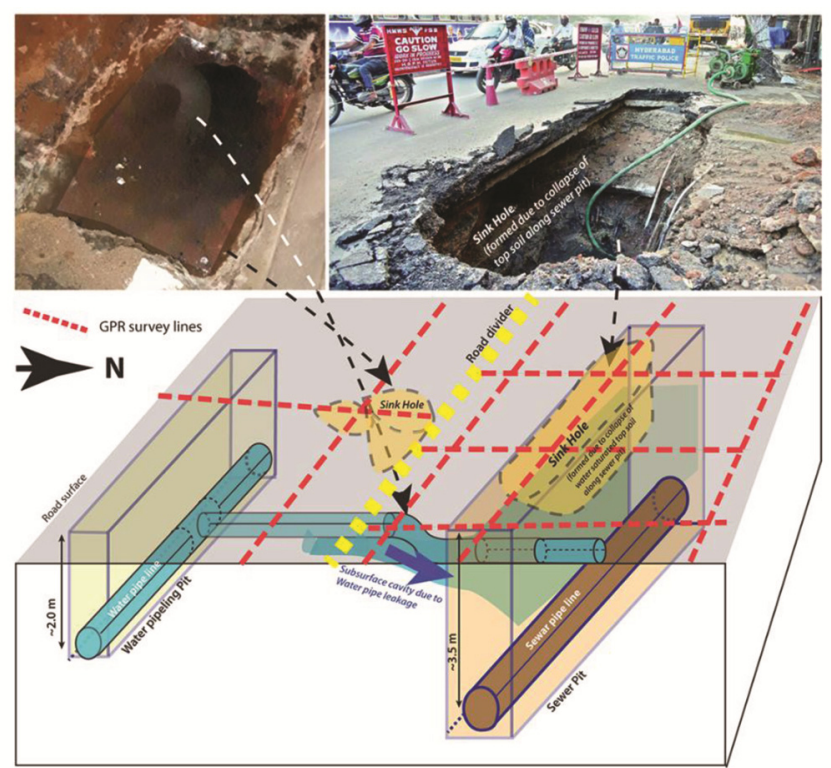

Figure 7. Schematic diagram summarizing the formation of sinkhole based on subsurface characterization of soil and civic utility in the affected zone. Red dotted lines are the position of the GPR profiles in zone 1; blue rod is the water pipeline and brown one is the sewer pipeline. The sinkholes are marked by the yellowish-brown polygons and the blue sheet below the water pipe is the leaked water flow.

sinkhole were confined to $\sim 2-2.5 \mathrm{~m}$ depth, except in the main sinkhole zone, where it extended to the sewage pipeline level (profiles 5, 19, 24 and 25).

The civic utilities like sewage and water supply routinely suffer from leakages due to addition of new infrastructures causing damage, malfunction and/or main- tenance issues. The problem becomes acute as local urban life depends on these utilities and the damaged roads create problem for commuters. In such a pressure situation, efforts are concentrated more towards addressing visible bigger problem, as often the subsurface is poorly understood. This kind of poor understanding or diagnosis usually lead to over enthusiastic response causing extra burden to the exchequer and unplanned expenditure. In the present study, we tried demonstrating the possible cause of sinkhole formation that helped in avoiding replacing the old sewage pipeline that involves high cost factor.

The GPR survey of the sinkhole-affected region (Figures 2 and 4) and 3-D survey of zone 1 (Figure 6) helped in understanding shallow subsurface configuration of sewage and water utilities and associated cavity in the region. The manholes and connecting sewage line clearly suggest that the trench of the sewage line would be $>3.5 \mathrm{~m}$ deep, and it would have been filled with the loose soil. To avoid contamination, it is always practiced that the main water pipeline is being laid on the other side of the road away from sewage line in a trench $\sim 2-2.5 \mathrm{~m}$ deep with multiple connecting pipes across the road as seen in the present case (Figure 6). If any leakage in the sewage pipeline occurs, it will affect only the sewage side and the sinkhole shall be extending up to the sever line depth, i.e. $3.5 \mathrm{~m}$. The subsurface imaging of cavity (Figure 6) suggests that the sinkholes and associated cavities show collapse at a shallower level and extend from sewage line side to the other side of the road where the water supply pipeline lies at a shallower depth. Further, the GPR image clearly illuminate that the saturated soil and cavity are present in profile sections $21,5,24$, 


\section{RESEARCH COMMUNICATIONS}

25 , but profile section 22 is unaffected, suggesting cavities are restricted to a very narrow zone (Figure 6).

The interaction with the civil contractor involved in the repair helped in understanding the alignment of water pipeline across the road. Based on GPR survey and ground truth from the contractor, a schematic 3D section of the sinkhole formation was developed (Figure 7). The shallow cavities in zone 1 were aligned parallel to the water pipeline from across the road and formed due to leakage in water pipeline at $\sim 2 \mathrm{~m}$ depth. Since the slope of the water pipeline trench was towards the larger sewage pipeline trench, any leakage from the water pipeline would contribute to the sewage trench. The water leakage would remove and carry the loose soil towards the sewage trench. This produced subsurface cavity causing road subsidence and formation of sinkhole, mostly along the sewage trench due to loss of bearing capacity of saturated loose soil.

Globally sinkhole formation related to civic utility represent a natural risk because of their abrupt nature without any clear detectible precursors affecting civic amenities and people. The present study along the Secunderabad clock tower-Patny Centre stretch of road in Secunderabad clearly demonstrated the effectiveness of GPR in subsurface mapping of cavity and identifying the pipeline leakage that caused the collapse of the road section. The identification of leakage in water pipeline helped in saving large budget in replacing the sewage pipeline. The mapping of subsurface extension of cavity was important for the safety of vehicles and pedestrians on such a busy street in Secunderabad. Thus, sinkhole monitoring and associated early warnings have significant importance in an urban society, and GPR plays a vital role in imaging the shallow subsurface features at high resolution.

1. Collins, M. E., Crum, M. and Hanninen, P., Using groundpenetrating radar to investigate subsurface karst landscape in North-Central Florida. Geoderma, 1994, 61, 1-15.

2. Chan, Y. A., Factors affecting sinkhole formation. Geo Report no. 28. Geotechnical Engineering Office, Civil Engineering Section, Hong Kong, 1994.

3. Salvati, R. and Sasowsky, I. D., Development of collapse sinkholes in areas of groundwater discharge. J. Hydrol., 2002, 264, 1-11.

4. Schoor, V., Detection of sinkholes using 2D electrical resistivity imaging. J. Appl. Geophys., 2002, 50, 393-399.

5. Kaufmann, O. and Quinif, Y., Cover-collapse sinkholes in the Tournaisis area, southern Belgium. Eng. Geol., 1999, 52, 15-22.

6. Brinkmann, R., Parise, M. and Dye, D., Sinkhole distribution in a rapidly developing urban environment: Hillsborough County, Tampa Bay area, Florida. Eng. Geol., 2008, 99, 169-184.

7. Caramanna, G., Ciotoli, G. and Nisio, S., A review of natura sinkhole phenomena in Italian plain areas. Nat. Haz., 2008, 45(2), 145-172.

8. Guarino, P. M. and Nisio, S., Anthropogenic sinkholes in the territory of the city of Naples (Southern Italy). Phys. Chem. Earth A, B C, 2012, 49, 92-102.

9. Krawczyk, C. M., Polom, U., Trabs, S. and Dahm, T., Sinkholes in the city of Hamburg - new urban shear-wave reflection seismic system enables high-resolution imaging of suberosion structures. J. Appl. Geophys., 2012, 78, 133-143.
10. Pandey, A. K., Nandan, M. J., Jaiswara, N. K., Dhar, S., Gogoi, Jonti, Kumar, K. S. and Sharma, N., Use of ground penetration radar (GPR) in mapping sinkhole developed along the stretch of road near Secunderabad Clock tower in Hyderabad, Telangana. Feasibility Study Report by CSIR-NGRI, 2017, p. 14.

11. Johnson, R. W., Glaccum, R. and Wojtasinski, R., Applications of ground-penetrating radar to soil survey. Soil Crop Sci. Soc. Fl. Proc., 1980, 39, 68-72.

12. Hunaidi, O. and Giamou, P., Ground-penetrating radar for detection of leaks in buried plastic water distribution pipes. In Proceedings of the 7th International Conference on Ground Penetrating Radar, Lawrence, KS, USA, 1998, 27-30, pp. 783-786.

13. Liu, G., Jia, Y., Liu, H., Qiu, H., Qiu, D. and Shan, H., A case study to detect the leakage of underground pressureless cement sewage water pipe using GPR, electrical and chemical data. Environ. Sci. Technol., 2002, 36, 1077-1085.

14. Singh, K. K. K., Ground penetrating radar study for hydrological conditions related with mining activity. Environ. Geol., 2003, 44, 20-27.

15. Krishnan, M. S., Geology of India and Burma, The Madras Law Journal Office, Madras, 1949, p. 573.

16. Neal, A., Ground-penetrating radar and its use in sedimentology: principles, problems and progress. Earth-Sci. Rev., 2004, 66, 261330 .

17. Mellett, J. S., Ground penetrating radar applications in engineering, environmental management, and geology. J. Appl. Geophys., 1995, 33, 157-166.

18. Benson, A. K., Applications of ground penetrating radar in assessing some geological hazards: examples of groundwater contamination, faults, cavities. J. Appl. Geophys., 1995, 33, 177-193.

19. Singh, K. K. K. and Chouhan, R. K. S., Stabilization of old unapproachable workings of XIII seam in Kari Jore using ground penetrating radar. Indian J. Radio Space Phys., 2000, 29, 88-93.

20. Singh, K. K. K. and Chouhan, R. K. S., Exploration of underground strata conditions for a traffic bypass tunnel using ground penetrating radar system: a case study. Geotech. Geol. Eng., 2002, 20, $81-87$.

21. Singh, K. K. K., Singh, S. K., Singh, A. K., Ghosh, C. N. and Singh, P. K., Role of MineVue radar for proving abandoned and unapproachable mine galleries for the safety of surface structures. J. Geol. Soc. India, 2018, 91, 195-197.

22. Annan, A. P. and Davis, J. L., Design and development of a digital ground penetrating radar system. In Ground Penetrating Radar (ed. Pilon, J.), Geological Survey of Canada, Paper 90-4, 1992, pp. 15-23.

23. dos Reis, J. A., de Castro, D. L., de Jesus, T. E. S. and Lima Filho, F. P., Characterization of collapsed paleocave systems using GPR attributes. J. Appl. Geophys., 2014, 103, 43-56.

24. Eyuboglu, S., Mahdi, H. and Al-Shukri, H., Detection of water leaks using ground penetrating radar. Department of Applied Science University of Arkansas at Little Rock, Arkansas, 72204, USA, 2003.

25. Kofman, L., Ronen, A. and Sam Frydman, S., Detection of model voids by identifying reverberation phenomena in GPR records. J. Appl. Geophys., 2004, 59(4), 284-299.

ACKNOWLEDGEMENTS. We thank the Director, CSIR-NGRI for providing facility for the study. We also thank our colleagues Sambudhha Dhar, Nilesh Kumar Jaiswara and Sravan Kumar for helping in GPR data acquisition. We appreciate cooperation of HMWSSB officials and contractor in providing priory information about depth and dimensions of sewage and drinking water pipelines and Telangana Police for regulating traffic during data acquisition. We highly appreciate reviewer's and editor's comments, which brought clarity to the manuscript.

Received 28 September 2018; revised accepted 25 July 2019

doi: $10.18520 / \mathrm{cs} / \mathrm{v} 117 / \mathrm{i} 10 / 1710-1715$ 